\title{
Csk-binding protein controls red blood cell development via regulation of Lyn tyrosine kinase activity
}

Janice H. C. PLANI-LAM ${ }^{1}$, Neli S. SLAVOVA-AZMANOVA ${ }^{1}$, Nicole KUCERA ${ }^{1}$, Alison LOUW $^{1}$, Jiulia SATIAPUTRA ${ }^{1}$, Peter SINGER ${ }^{1}$, Kong-Peng Lam ${ }^{2}$, Margaret L. HIBBS ${ }^{3}$ and Evan INGLEY ${ }^{1}$

$1 \quad$ Cell Signalling Group, Laboratory for Cancer Medicine, Harry Perkins Institute of Medical Research and Centre for Medical Research, The University of Western Australia, WA 6009, Australia.

2 Laboratory of Immunology, Bioprocessing Technology Institute, Agency for Science, Technology and Research, 20 Biopolis Way, \#06-01 Centros, Singapore 138668, Singapore.

3 Leukocyte Signalling Laboratory, Department of Immunology, Alfred Medical Research and Education Precinct, Monash University, Melbourne, VIC, Australia.

* Corresponding Author:

Associate Professor Evan Ingley

Harry Perkins Institute of Medical Research

Level 7, QQ Building

6 Verdun Street

NEDLANDS, WESTERN AUSTRALIA 6009

Telephone: 61-08-6151-0738

Facsimile: 61-08-6151-0701

Email: evan.ingley@uwa.edu.au

Running title: Cbp controls Lyn erythroid viability signaling.

Abstract word count: 248.

Main text word count: 3950.

Number of Figures: 7.

Number of Tables: 0.

Number of Supplemental files: 3. 


\begin{abstract}
Erythropoiesis is principally controlled through erythropoietin (Epo)-receptor signaling, which involves JAK2 and Lyn tyrosine kinase; both important for regulating red blood cell development. Negative regulation of Lyn involves Csk-mediated phosphorylation of its C-terminal tyrosine, facilitated by the transmembrane adaptor Csk-binding protein (Cbp). While Cbp has significant functions in controlling Lyn levels and activity in erythroid cells in vitro, its importance to primary erythroid cell development and signaling has remained unclear. To address this, we assessed the consequence of loss of Cbp on the erythroid compartment in vivo, and whether Epo-responsive cells isolated from Cbp knockout mice exhibited altered signaling. Our data show that male $\mathrm{Cbp}^{-/}$mice display a modest but significant alteration to late erythroid development in bone marrow with evidence of increased erythrocytes in the spleen, while female $C b p^{-/}$mice exhibit a moderate elevation in early erythroid progenitors (not seen in male mice) which does not influence the later steps in red blood cell development. In isolated primary erythroid cells and cell lines generated from $\mathrm{Cbp}^{-/-}$mice, survival signaling through Lyn/Akt/FoxO3 was elevated, resulting in sustained viability during differentiation. The high Akt activity disrupted GAB2/SHP-2 feedback inhibition of Lyn, however the elevated Lyn activity also increased inhibitory signaling via SHP-1 to restrict the Erk1/2 pathway. Interestingly, while loss of Cbp led to mild changes to late red blood cell development in male mice, this was not apparent in female $\mathrm{Cbp}^{-/-}$mice, and is potentially due to their elevated estrogen, which is known to facilitate early progenitor self-renewal.
\end{abstract}

Key words: Erythropoiesis, Erythropoietin, Lyn, Csk-binding protein, signaling, cell survival. 


\section{Introduction}

Signalling downstream of the erythropoietin receptor $(E p o R)$ requires the activation of JAK2, but also involves Src family kinases (SFK) to facilitate dynamic signaling. ${ }^{1-7}$ We have shown that the SFK Lyn is important for viability and differentiation signals elicited by erythropoietin (Epo) in erythroid progenitors from Lyn knockout mice, signalling principally through Akt/FoxO3. ${ }^{8-12}$ Further, erythroid cells expressing a gain-of-function mutant form of Lyn ( $L y n^{\text {up }}$, Y508F) showed pronounced Akt/FoxO3 signaling that enhanced viability but delayed differentiation. ${ }^{10}$ Lyn also appears critical for providing negative feedback via SHP-1 to restrict Erk1/2 signalling and JAK2 activation. ${ }^{11,13}$ Consequently, the regulation of Lyn activity is important for controlling erythropoiesis, with gain- and loss-of-function Lyn mutant mice showing significant erythroid phenotypes. ${ }^{9-11,13}$

Controlling SFK activity, including that of Lyn, is mediated by phosphorylation of activating and inhibitory sites, as well as by protein-protein interactions. ${ }^{14}$ In its inactive form, Lyn has two main intramolecular interactions, its SH3 domain binds to a site linking the $\mathrm{SH} 2$ and kinase domains, and its $\mathrm{SH} 2$ domain binds to the phosphorylated $\mathrm{C}$-terminal tyrosine motif (Y508 site). The principal kinase mediating phosphorylation of the inhibitory C-terminal Y508 site and inactivation of the enzyme is C-Src kinase (Csk). ${ }^{15-18}$ In the active configuration, Lyn is dephosphorylated on Y508 and phosphorylated on the activation loop tyrosine (Y397), thereby rendering the enzyme's SH3 and $\mathrm{SH} 2$ domains available to ligate high affinity motifs in adaptor/scaffold molecules. The subcellular location of Lyn is also regulated by ligation of its $\mathrm{SH} 3 / \mathrm{SH} 2$ domains and lipid modification of its $\mathrm{N}$-terminus; myristoylation and palmitoylation promote compartmentalization in to lipid rafts. ${ }^{19,20}$

Csk-binding protein ( $\mathrm{Cbp}$, also known as PAG1 for phosphoprotein associated with GEMs; glycosphingolipid enriched microdomains) is primarily restricted to lipid rafts and is phosphorylated by activated SFKs (including Lyn), which mediates high affinity SH2 domain-directed binding of SFKs and Csk to specific pY motifs on Cbp, to orchestrate dynamic localized inactivation of activated SFKs. ${ }^{17,18,20-22}$ Within erythroid cells we have shown that Epo-induced activation of Lyn mediates phosphorylation of Cbp to recruit Csk to achieve the spatial/temporal signalling dynamics of Lyn. ${ }^{17}$ However, the critical importance of $\mathrm{Cbp}$ for primary erythroid cell development and signaling has remained unclear. Consequently, we anaysed the loss of Cbp on the erythroid compartment in vivo and erythroid cell signaling. We found significant alterations to late erythroid development in the bone marrow of male $\mathrm{Cbp}^{-/}$mice, and in isolated primary erythroid cells and cell lines generated from $\mathrm{Cbp}^{-/}$mice, viability signaling through $\mathrm{Akt} / \mathrm{FoxO} 3$ was increased that resulted in increased viability during differentiation. The high Akt activity in $\mathrm{Cbp}^{-/-}$cells 
disrupted GAB2/SHP-2 feedback inhibition of Lyn and the elevated Lyn activity also increased inhibitory signaling via SHP-1 to restrict the Erk1/2 pathway. Interestingly, alterations to late red blood cell development was only apparent in male mice, potentially due to the elevated estrogen in female mice which facilitates more early progenitor selfrenewal. ${ }^{23}$ Taken together, these biological and biochemical experiments suggest that $\mathrm{Cbp}$ has a critical role in erythroid cells to facilitate control of Lyn activity downstream of the Epo-receptor, for its promotion of viability signaling to Akt/FoxO3 and negative feedback of Erk1/2 and JAK2 via SHP-1/2. 


\section{Mice, primary erythroid cell analysis and erythroid cell line generation}

C57BL/6J and $\mathrm{Cbp}^{-/}$(on a C57BL/6J background, backcrossed $>20$ generations) ${ }^{24}$ mice were used at day 12.5-13.5 of embryonic development for the generation of erythroid cell lines, ${ }^{25}$ and as 8-15 week old adults for flow cytometric analysis of bone marrow, spleen and blood parameters. Heparinised paediatric tubes were used for blood collection and blood cell parameter determination on an Advia 120 (Siemens, Deerfield, IL). Immortalized erythroid cell lines were generated as described ${ }^{25}$ and analysed as described in Supplemental material. Male and female lines were generated and showed no significant gender-specific alterations to cell biology or signaling parameters. For analysis undertaken here we utilized only female cell lines (Supplemental Figure S1). Primary cell isolation and analysis for signaling experiments were as previously described ${ }^{26}$ and in Supplemental material. Cell morphology was examined microscopically, following cytocentrifugation and Wright's Giemsa staining with, or without, neutral benzidine staining for haemoglobin ${ }^{27}$. All animal experiments were performed in accordance with National Health and Medical Research Council of Australia guidelines for animal experimentation, with approval from the Royal Perth Hospital, Perth (Western Australia).

\section{Flow cytometry}

Flow cytometry of single cell suspensions of bone marrow, spleen and cultured erythroid cells was employed to assess cell surface expression using fluorophorconjugated antibodies as described in Supplemental material.

\section{Cell lysis, immunoblotting and immunoprecipitation}

HEK293T cells (cultured in DMEM/10\% FCS) were used for transient expression experiments with plasmids transfected using Lipofectamine2000 (Life Technologies) as per the manufacturer's instructions. HEK293T and erythroid cells were lysed and analysed by immunoblotting and immunoprecipitation as described in Supplemental material.

\section{Recombinant protein expression, purification and interaction analysis}

All plasmid constructs were generated by site directed mutagenesis, using oligonucleotides (sequences available upon request), and subcloned into the appropriate vector and confirmation by Sanger sequencing. The myc-tagged $\mathrm{Cbp}$ expression

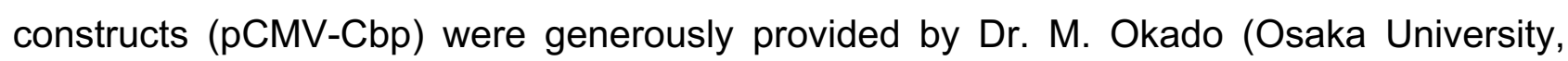


Japan $)^{22}$. The construction of the murine Lyn expression plasmid pCA-LynY508F has been previously described. ${ }^{8}$ The generation, expression, purification and subsequent analysis of recombinant protein interaction by bio-layer interferometry was undertaken as described in Supplemental material.

\section{Statistical analysis}

For general statistical analysis experiments were repeated as three biological replicates and analysed by student's t-test or ANOVA with two-tailed analysis (GraphPad Prism, v6.0f, GraphPad Software, San Diego, CA). 


\section{Results}

\section{Cbp knockout mice have altered erythropoiesis.}

To examine the role of $\mathrm{Cbp}$ in erythroid development we analysed the blood, bone marrow and spleen of adult mice, comparing C57BL/6 control mice to Cbp ${ }^{-/-}$mice. ${ }^{28}$ Since it is now known that there are sex differences in erythropoiesis, ${ }^{23}$ mice were analysed according to sex and genotype. Blood parameters comparing $\mathrm{Cbp}^{-/}$and control mice, irrespective of sex, showed no major alterations (no alterations to MCV or MCH), but female $\mathrm{Cbp}^{-/}$displayed elevated RBC numbers compared to male $\mathrm{Cbp}^{-/}$mice (Supplemental Figure S2A, B). While total cell counts of bone marrow were not significantly different between control and $\mathrm{Cbp}^{-/-}$(male or female) mice, the bone marrow from male $\mathrm{Cbp}^{-/}$mice displayed a clear relative reduction of mature (haemoglobin positive) red blood cells $(\mathrm{RBC})$ (Figure $1 \mathrm{~A}$ ), which was not seen in female mice, and could be quantitated by a significant reduction of $\operatorname{Ter} 119^{+} / \mathrm{CD} 71^{-}$mature erythrocytes as a proportion of total bone marrow cells (Figure-1B). We observed a significant reduction in committed expanding/differentiating erythroblasts (Ter $119^{+} / \mathrm{CD} 71^{\text {low-high }}$ ), but elevated proerythroblasts $\left(\right.$ Ter119 $/ \mathrm{CD} 71^{+}$) in the bone marrow of male mice (Figure 1B). This suggested maturation dynamics was altered in the bone marrow of male $\mathrm{Cbp}^{-/-}$mice. We then analysed the size (FCS) and CD44 expression of Ter119 $/$ CD $71^{\text {low-high }}$ cells to subdivide the erythroblasts into distinct maturation stages (Figure 1B). ${ }^{29}$ This showed bone marrow erythroblasts from male $\mathrm{Cbp}^{-/-}$mice had significantly retarded maturation, which was not seen in female mice (Figure 1B, Supplemental Figure S2C, D). We then analysed bone marrow differentiation capacity ex vivo and found that all showed significantly elevated hemoglobin production in the presence of Epo (Supplemental Figure 3A). However, bone marrow from male $\mathrm{Cbp}^{-/-}$mice had reduced hemoglobin production compared to male control animals, while female $\mathrm{Cbp}^{-/}$mice showed no such deficit (Supplemental Figure 3A).

While male mice displayed no significant differences in early progenitors within the bone marrow, namely the common myeloid progenitor (CMP), granulocyte/macrophage progenitor (GMP) and megakaryocyte/erythroid progenitor (MEP) (Supplemental Figure S2E), we observed a significant elevation of GMP and a trend $(p=0.088)$ for increased MEP in the bone marrow of female $\mathrm{Cbp}^{-/-}$animals compared to controls (Figure $1 \mathrm{C}$ ).

Having observed gender-specific abnormalities in the bone marrow of $\mathrm{Cbp}^{-/-}$mice, we then analysed their spleen, for extramedullary emergency erythropoiesis. Male Cbp ${ }^{-/-}$ mice had significantly heavier spleens relative to total body weight than female $C b p^{-/-}$ 
animals (Figure 1D), which also appeared to contain more mature erythrocytes than wildtype male mice (Figure $1 \mathrm{E}$ ). Indeed, the spleen from male $\mathrm{Cbp}^{-/-}$mice showed increased numbers of mature erythrocytes compared to control animals (Figure 1F). However, no significant increase in erythroid progenitors or alterations to erythroid development was detected in the spleens of male or female $\mathrm{Cbp}^{-/}$mice (Figure $1 \mathrm{~F}$, and data not shown).

\section{Erythroid cell lines from Cbp knockout mice show increased Epo-independent viability and exhibit elevated differentiation.}

Foetal liver erythroblasts express both Lyn and Cbp, however during their maturation, Lyn levels increase and Cbp expression is essentially lost (Supplemental Figure S4A, B). We generated immortalized cell lines from foetal liver pro-erythroblasts of Cbp-/- and control mice to study their biology and signaling. Microscopic analysis and cell surface expression illustrated that the wild-type (J2-WT) and $\mathrm{Cbp}^{-/-}\left(\mathrm{J} 2-\mathrm{Cbp}^{-/-}\right)$cell lines were at an equivalent pro-erythroblast stage (Figure $2 A, B$ ).

In full growth media, and in differentiation media (IMDM with $\mathrm{T}_{3}$-depleted FCS) in response to Epo $(1 \mathrm{U} / \mathrm{ml})$, both cell lines (J2-WT and $\left.\mathrm{J}^{-}-\mathrm{Cbp}^{-/-}\right)$displayed high viability and proliferated at equivalent rates (Figure 2C). However, when placed into differentiation media, only $\mathrm{J}^{-}-\mathrm{Cbp}^{-/-}$cells maintained a high viability in the absence of Epo (Figure 2D, Supplemental Figure S7).

Significantly, $\mathrm{J}^{-}-\mathrm{Cbp}^{-/-}$cells showed a greater propensity to differentiate in terms of the number of cells producing haemoglobin, as assayed by Benzidine staining (Figure 2E), as well as the total amount of haemoglobin produced (Figure 2F). Interestingly, both J2WT and $\mathrm{J}^{2}-\mathrm{Cbp}^{-/-}$cell lines showed similar dynamics in response to Epo of the rate-limiting haem synthesizing erythroid enzyme ALAS-E (Figure 2G). However, J2-Cbp ${ }^{-/-}$cells had more robust globin production during differentiation (Figure 2G). Interestingly, more J2$\mathrm{Cbp}^{-/-}$cells appeared to maintain cell surface expression of the transferrin receptor (CD71) in response to Epo during differentiation, compared to J2-WT cells (Figure 2H). Consequently, the increased differentiation of $\mathrm{J} 2-\mathrm{Cbp}^{-/-}$cells may be due to an increased capacity to import transferrin/Fe as well as increased synthesis of globin protein. Additionally, the increased viability of ${\mathrm{J} 2-\mathrm{Cbp}^{-/}}^{-}$cells would allow more cells to proceed through differentiation especially at lower Epo levels, which would also result in increased numbers of differentiating cells, as was observed.

Lyn phosphorylates $\mathrm{Cbp}$ and mediates direct binding of SFKs (Lyn, Src) and Csk, and $\mathrm{Cbp}^{-/-}$erythroid cell lines have elevated lipid raft associated SFK activity. 
Utilizing the isolated Lyn kinase domain ${ }^{30}$ and the purified cytoplasmic region of $\mathrm{Cbp}$, we show that Cbp is phosphorylated directly by Lyn (Figure 3A). This phosphorylation of $\mathrm{Cbp}$ generates high affinity binding sites for the $\mathrm{SH} 2$ domains of $\mathrm{Src}$ and Lyn with similar real-time binding kinetics (Figure 3B). Using the purified SH2 domain of Csk labeled with HRP as a direct Western blotting reagent, we show that it binds strongly to Cbp that has been phosphorylated by constitutively active Lyn (LynY508F) only when the Y314 site is present within Cbp (Figure 3C). Further, the level of phosphorylation of this site, as measured by $\mathrm{SH} 2$ domain binding, is markedly enhanced when the Y381/409 sites are present, which mediate strong interaction with the SH2 domain of Lyn. This suggests that Lyn does not readily phosphorylate the Y314 site directly, unless Lyn is in a strong complex with Cbp through its $\mathrm{SH} 2$ domain. When the Y314 site of $\mathrm{Cbp}$ is phosphorylated, it directs high affinity binding of the $\mathrm{SH} 2$ domain of Csk (Figure 3D). These, and other data, ${ }^{15}, 17,18,21,22,31$ strongly implicate $\mathrm{Cbp}$ as a major mediator of inactivation of Lyn, consequently its loss in erythroid cells should also result in elevated Lyn activity. Indeed, in J2-Cbp ${ }^{-/-}$erythroid cells we found substantially elevated levels of active Lyn as evidenced by its phosphorylation within the activation loop (SFK-Y416 motif, Y397 in Lyn), particularly in lipid rafts (Figure 3E, R-fraction). Significantly, this elevated Lyn activity in Cbp-deficient erythroid cells also elicited an enhanced activation of STAT5 upon Epo-R ligation suggesting there are major down-stream ramifications for the elevated Lyn activity in these cells for Epo signaling (Figure 3E), especially as the Epo-R signaling complex and STAT5 can be recruited to lipid rafts that contain active Lyn. ${ }^{32}$ Indeed, a survey of global phospho-tyrosine alterations during Epo-induction in WT and $\mathrm{Cbp}^{-/}$cells showed that several proteins had marked changes in their intensity and dynamics during stimulation (Figure 3F).

\section{Elevated Akt and SHP-1 pathway activation in erythroid cell lines from Cbp knockout mice.}

We next investigated known down-stream pathways of Lyn and Epo-R in more detail (Figure 4). Here we found that JAK2 activation was essentially normal, however, the Epo-R itself displayed substantially reduced phosphorylation in $\mathrm{J}^{-}-\mathrm{Cbp}^{-1-}$ cells (Figure $4 \mathrm{~A}$ ). This may suggest that activation of the Epo-R/JAK2 complex was normal but its inactivation was elevated in $\mathrm{J}^{-}-\mathrm{Cbp}^{-1-}$ cells. Further, both STAT5 and Akt showed enhanced activation; while Erk1/2 displayed reduced activation in $\mathrm{J}_{2}-\mathrm{Cbp}^{-/}$cells compared to J2-WT cells in response to Epo (Figure 4A). 
We then looked at signaling intermediates and other down-stream components that influence the Epo-R cascade (Figure 4B). Importantly, cells lacking Cbp failed to switch on Epo-induced downregulation of Lyn via phosphorylation of the inhibitory C-terminal tyrosine (Y508) of Lyn, supporting the role of $\mathrm{Cbp}$ in recruiting Csk to mediate phosphorylation of this inhibitory site (Figure 4B). Putting both the activation loop and inhibitory C-terminal site phosphorylation dynamics together shows that Epo-induced a strong dynamic activation followed by inhibition in J2-WT cells, while $\mathrm{J}^{-}-\mathrm{Cbp}^{-/}$cells have constitutively activated Lyn (Supplemental Figure S5). The phosphatase SHP-1, an important substrate of Lyn, was prominently and constitutively activated in $\mathrm{J} 2-\mathrm{Cbp}^{-/-}$cells, which could explain the reduced Epo-R phosphorylation and Erk1/2 activation in these cells (Figure 4A, B). ${ }^{33,34}$ No major alteration to SHP-2 phosphorylation dynamics was seen in $\mathrm{J} 2-\mathrm{Cbp}^{-/}$cells (Figure 4B). The adaptor GAB2 has inhibitory serine phosphorylation mediated by Akt and activation tyrosine phosphorylation facilitated by Lyn. ${ }^{10,11,35-38}$ Interestingly, in $\mathrm{J}^{-}-\mathrm{Cbp}^{-/-}$cells the elevated Akt activity appeared to dominate over the enhanced Lyn activity resulting in enhanced inhibitory S159 phosphorylation and loss of the activation Y452 phosphorylation (Figure 4B). In J2-Cbp ${ }^{-/-}$cells, the elevated Akt activity correlated with enhanced and more sustained phosphorylation of FoxO3, but did not mediate a significant alteration to GSK3 phosphorylation (Figure 4B, Supplemental Figure S6). Lyn also intersects the phospholipase-C $\gamma 1 / 2$ (PLC $\gamma 1 / 2)$ pathways, ${ }^{39,} 40$ and J2-Cbp ${ }^{-/-}$ cells showed elevated PLC $\gamma 1$ phosphorylation after Epo addition (Figure 4B). We then looked at the level of $\mathrm{Bcl}-2$ and SOCS family members that may account for viability alterations. Interestingly, no significant changes to BAD, BCl-xL, SOCS1, SOCS3 or CIS were noted in the $\mathrm{J} 2-\mathrm{Cbp}^{-/-}$cells compared to J2-WT cells (Figure $4 \mathrm{C}$ ).

\section{Erythroid cell lines from Cbp knockout mice show elevated Akt signaling to} translational regulators, and increased interaction of Akt and Lyn.

One of the major pathways regulated by Akt is that of translation control. ${ }^{44}$ Elevated

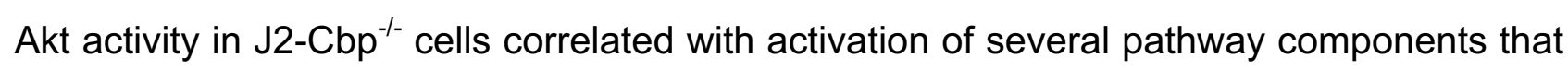
promote translation (i.e. p70S6K, elF4E and 4E-BP1), but also increases in an inhibitory marker (i.e. phosphorylation of elF $2 \alpha$ ) (Figure 5A). Overall, phosphorylation of the proximal translation regulator S6 was not significantly elevated in $\mathrm{J} 2-\mathrm{Cbp}^{-/-}$cells, with a delayed but equivalent maximal activation of S6 phosphorylation in $\mathrm{J} 2-\mathrm{Cbp}^{-/-}$cells (Figure $5 A)$.

A link between Akt and Lyn has been suggested in previous studies, both directly and indirectly, ${ }^{41,42}$ and with Akt and Lyn both activated in $\mathrm{J}^{4-\mathrm{Cbp}^{-/}}$cells, we investigated 
the degree of interaction of these two proteins. In both J2-WT and J2-Cbp ${ }^{-/-}$cells Lyn and Akt could be co-immunoprecipitated, however, the interaction was significantly enhanced in the $\mathrm{J} 2-\mathrm{Cbp}^{-/-}$cells at the 0 and $1.5 \mathrm{~min}$ time points (Figure 5B). Further, the potential for direct activation of Akt by tyrosine phosphorylation ${ }^{43}$ by Lyn in these complexes was supported by the observation that in $\mathrm{J}^{-}-\mathrm{Cbp}^{-/-}$cells, significant $\mathrm{Y} 315$ site phosphorylation of Akt could be observed after Epo stimulation (Figure 5A).

\section{Enhanced Akt/FoxO3 signaling in erythroid cell lines from Cbp knockout mice during differentiation.}

Here we undertook immunoblot analysis of J2-WT and J2-Cbp ${ }^{-/-}$cells at 0 and $48 \mathrm{~h}$ in differentiation media with and without Epo (Figure 6A). The elevated Akt activity observed in short-term Epo-induction was also observed in long-term differentiation conditions in the $\mathrm{J} 2-\mathrm{Cbp}^{-/-}$cells, which also correlated with phosphorylation of FoxO3 (and a moderate increase in GSK3 phosphorylation) (Figure 6A). Interestingly, even in the absence of exogenous Epo, $\mathrm{J}-\mathrm{Cbp}^{-/}$cells displayed substantial activation of Akt and phosphorylation of FoxO3, suggesting that the elevated Lyn activity in $\mathrm{J}^{-}-\mathrm{Cbp}^{-/}$cells was linked to Akt/FoxO3 independent of ligation of the Epo-R. Activation of STAT5 was fully dependent on Epo addition, as was maintaining a pro-viability ratio of $\mathrm{Bcl}_{\mathrm{XL}}$ to BAD. Both

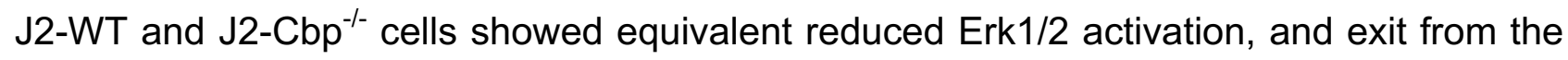
cell cycle (as marked by increased p27Kip1) during the Epo-induced differentiation process (Figure 6A).

\section{Primary erythroid cells from Cbp knockout mice have elevated Akt/FoxO3 signaling and SHP-1 pathway activation.}

We next sought to determine if the signaling alterations observed in the immortalized erythroid cells were recapitulated in non-immortalized primary cells. Using splenic erythroblasts isolated from phenylhydrazine-treated mice (enriched for CFU-E/proerythroblasts) we undertook short-term signaling analyses in response to Epo addition (Figure 6B). Importantly, the alterations observed in the immortalized cell lines were recapitulated in primary cells (compare Figure 4 and 6B). Specifically, in $\mathrm{Cbp}^{-/-}$cells the level of phosphorylation of the Epo-R was reduced, while STAT5 activation was enhanced. The Akt/FoxO3 pathway and SHP-1 phosphorylation were enhanced in $\mathrm{Cbp}^{-/}$cells, while Erk1/2 activation was less pronounced. The elevated phospho-FoxO3 showed a strong increase when expressed relative to total FoxO3 levels which are reduced in the $\mathrm{Cbp}^{-/-}$ cells (Figure $6 B$ ). Further, elevated inhibitory serine phosphorylation of GAB2 was also 
observed in $\mathrm{Cbp}^{-/}$cells, which correlated with reduced tyrosine phosphorylation, while no major changes to SHP-2 phosphorylation were seen (Figure 6B). We also assessed Akt phosphorylation dynamics in the bone marrow differentiation cultures from male and female $\mathrm{Cbp}^{-/}$and control mice (Supplemental Figure 3S). While no gender-specific alterations to pAkt were observed, $\mathrm{Cbp}^{-/}$lysates consistently showed higher pAkt levels compared to control bone marrow cultures (Supplemental Figure 3B). 


\section{Discussion}

In this study we provide compelling evidence for the transmembrane adaptor $\mathrm{Cbp}$ (PAG1) being an important regulator of the SFK Lyn in erythroid cells through analysis of primary and immortalized $\mathrm{Cbp}^{-/-}$erythroid cells and the erythroid compartment of $\mathrm{Cbp}^{-/-}$ mice. We show (summarized in Figure 7) that loss of Cbp results in increased Lyn activity that feeds into several down-stream pathways resulting in enhanced Akt/FoxO3 viability signaling, STAT5 phosphorylation, and elevated SHP-1 feedback inhibition of Epo-R phosphorylation and Erk1/2 activity. This results in increased viability of erythroid cells in vitro as they proceed through differentiation. At the physiological level, peripheral blood parameters were not significantly altered in $\mathrm{Cbp}^{-/-}$mice compared to control animals. However, there was a modest difference in RBC numbers between male and female $C b p^{-/-}$ mice that is normally seem in the background strain used in these studies (C57BL6/J). ${ }^{45}$ Further, we observed a mild alteration to the maturation dynamics of bone marrow erythroid cells in male $\mathrm{Cbp}^{-/-}$mice in vivo (with disproportionately relatively more early differentiating erythroid cells), and reduced ex vivo differentiation capacity, while in female $\mathrm{Cbp}^{-/}$mice we saw moderate alterations to early multi-lineage progenitors. This genderbiased physiological difference could potentially be explained by the estradiol regulation of

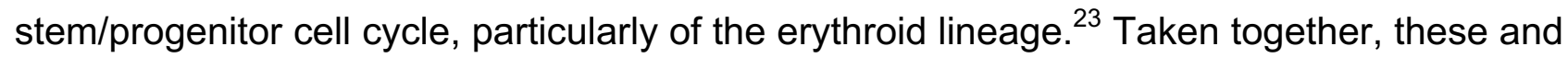
previous results support the notion that $\mathrm{Cbp}$ is important for regulating SFK activity, and that this does have detectable but modest functional biological consequences.

Previously we identified Lyn as key in regulating viability and differentiation during erythroid development using both Lyn knockout mice, as well as mice harbouring constitutively active Lyn. ${ }^{9-11,13}$ These findings have also been strongly supported by other studies. $^{6,40,46}$ Further, we identified Cbp as a very important regulator of Lyn activity and protein levels through recruiting Csk/Ctk and SOCS1 in the J2 erythroid cell line. ${ }^{17,} 18$ Consequently, we speculated that Cbp deficient mice and their erythroid cells would display signaling and phenotypic alterations similar to those with elevated Lyn activity, such as the $L y n^{u p}$ (Y508F) mice. ${ }^{10}$ Comparison of signaling in $C b p^{-/}$and $L y n^{u p}$ cells ${ }^{10}$ shows many similarities; activation of Akt/FoxO3 viability, enhanced STAT5 phosphorylation, elevated inhibitory serine phosphorylation of GAB2, and increased negative feedback inhibition of Epo-R and Erk1/2 via SHP-1 (Figure 7A). However, in Cbp deficient cells, signaling pathway changes were milder than those in $L y n^{u p}$ cells. This is likely due to the Lyn protein in $\mathrm{Cbp}^{-/-}$cells still available for phosphorylation and inhibition by Csk/Ctk (indeed low Lyn-Y508 site phosphorylation could be detected in these cells) but this could not be regulated by $\mathrm{Cbp}$ and was not significantly altered by Epo-addition 
(Figure 7B). In $\mathrm{Cbp}^{-/}$erythroid cells this results in increased viability during differentiation. In contrast to $L y n^{u p}$ erythroid cells that have enhanced viability but delayed differentiation, ${ }^{10}$ the $\mathrm{Cbp}^{-/}$cells had enhanced viability but not at the expense of differentiation. Indeed, they were more responsive to Epo-induced differentiation than wildtype cells. Interestingly, the physiological phenotypes of $\mathrm{Cbp}^{-/}$and $L y n^{u p}$ mice were distinct, with $L y n^{u p}$ mice displaying major alterations to mature RBCs and strong activation of stress/emergency erythropoiesis, features that were not seen in $\mathrm{Cbp}^{-/}$mice. ${ }^{10}$ This could be explained by the fact that Lyn is expressed throughout erythropoiesis, from progenitors to mature RBCs, and indeed is an important regulator of mature RBC function, ${ }^{10,47,48}$ while Cbp appears restricted to precursor cells. ${ }^{18}$ Additionally, in Cbp ${ }^{-1-}$ erythroid cells Csk is still intact and capable of regulating Lyn to a degree through Cbpindependent mechanisms, thus reducing the extent of signaling alteration and biological consequences, compared to $L y n^{\text {up }}$ cells/mice (where the Y508 site cannot be phosphorylated).

The Epo-stimulated viability of erythroid cells and their initiation of exit from the cell cycle during differentiation are in part mediated by Akt-directed phosphorylation of FoxO3. ${ }^{49-51}$ FoxO3 also appears important during the latter stages of differentiation for reducing oxidative stress triggered by high levels of haemoglobin that accumulate during erythroid differentiation as well as cell cycle exit. ${ }^{52}$ We observed that phosphorylated Akt and FoxO3 were clearly cytoplasmic 30 min post-Epo-stimulation of $\mathrm{Cbp}^{-/-}$cells. This is consistent with the inhibition of $\mathrm{FoxO} 3$ through phosphorylation and cytoplasmic compartmentalization (via binding 14-3-3 proteins) to promote viability. Interestingly, FoxO3 activation and nuclear localization in erythroid cells is needed late in their maturation when haemoglobin levels are high, to mitigate ROS accumulation. ${ }^{52}$

Other alterations to down-stream Epo-R pathways that were affected in $\mathrm{Cbp}^{-/}$cells are consistent with previous studies where Lyn activity/levels have been manipulated, i.e. STAT5, GAB2, SHP-1 and Erk1/2. ${ }^{10}{ }^{11}$ Moreover, in hematopoietic cells in general it appears Lyn is important for the negative control of Erk1/2 through SHP-1, via several receptor systems. ${ }^{13,33,53,54}$

Interestingly, the degree of activation of Lyn in $\mathrm{Cbp}^{-/}$cells is significantly less than that of $L y n^{u p}$ cells. This could be due to the fact that Csk/Ctk are still able to interact/inactivate Lyn as well as other SFKs in the $\mathrm{Cbp}^{-/}$cells, or alternatively, Csk/Ctk adaptors could facilitate phosphorylation of the C-terminal SFK tyrosine residue. In this regard, it is clear that in $\mathrm{T}$ - and $\mathrm{B}$-cells there are alternative transmembrane adaptors that can interact with SFKs and Csk that could well compensate for any Cbp deficiency (i.e. in 
$\mathrm{Cbp}^{-/}$mice $)^{24,55}$ and provide regulated control of SFK activity. Further, the mild phenotype of $\mathrm{Cbp}^{-/-}$mice is in stark contrast to the embryonic lethality of $\mathrm{Csk}^{-/}$mice, further supporting alternative mechanisms that Csk can employ to regulate SFK activity in $\mathrm{Cbp}^{-/}$cells. ${ }^{56}$ Indeed, while SFKs are very important for T- and B-cell signaling and biology, the lack of major phenotypes of these compartments in $\mathrm{Cbp}^{-/}$mice would initially appear surprising. However, several T- and B-cell expressed adaptors have sequence and/or functional overlap with $\mathrm{Cbp}$ that are known to bind Csk and could well provide additional negative regulatory control of SFKs, i.e. $\mathrm{LIME}^{57,58}$ and SIT. ${ }^{59}$ It would be beneficial to address this important point of functional redundancy of these SFK-regulating transmembrane adaptors by analyzing cells/mice with Cbp and LIME/SIT deleted. There are several additional adaptors/scaffolds that can bind Csk (e.g. paxillin, IRS, caveolin-1, SgK223) ${ }^{60}$ which could also mediate subcellular specific regulation of SFKs through Csk, and thus provide partial functional redundancy for loss of $\mathrm{Cbp}$ within their respective signaling complexes.

An important additional mode of regulation of SFKs is via phosphatases, which can provide both activation through dephosphorylation of the negative C-terminal tyrosine (e.g. CD45), or inhibition through phosphatase activity towards the activation loop tyrosine (e.g. PEP). Interestingly, Csk forms a strong complex with PEP via its $\mathrm{SH} 3$ domain, ${ }^{61}$ and thus when Csk interacts with $\mathrm{Cbp}$ via its $\mathrm{SH} 2$ domain (directed to the pY314 site), it would juxtapose a phosphatase (PEP) that can mediate inactivation as well as Csk's phosphorylation of the C-terminal tail. Consequently, loss of Cbp would be expected to enhance SFK activity through reduced Csk-directed PEP-mediated inactivation. Indeed, consistent with this notion we did find increased phosphorylation of Lyn on its activation loop tyrosine in Cbp deficient cells (Figure 7).

Overall our findings illustrate that $\mathrm{Cbp}$ is an important regulator of Csk recruitment to the SFK Lyn in Epo-responsive erythroid cells. Consequently, loss of Cbp (Figure 7) results in elevated Lyn activity promoting the activation of down-stream pathways known to be regulated by this enzyme in erythroblasts (i.e. Akt/GAB2/FoxO3, STAT5, SHP$1 /$ Erk1/2), which results in their increased viability and enhanced differentiation. However, these biochemical alterations only induce mild changes to the differentiation profile of erythroblasts in the bone marrow of male $\mathrm{Cbp}^{-/}$mice. 


\section{Author contribution}

Contribution: Janice H.C. Plani-Lam, Neli S. Slavovoa-Azmanova and Nicole Kucera designed, supported and performed experiments, and analysed data. Alison Louw, Juliana Satiaputra and Peter Singer performed experiments. Kong-Peng Lam supported the research, provided analysis of results and contributed to writing the manuscript. Margaret L. Hibbs supported the research, designed experiments, analysed results and contributed to writing the manuscript. Evan Ingley designed and supported the research, designed and undertook experiments, analysed data and wrote the manuscript.

\section{Acknowledgements}

We thank Cindy Le, Adley Handoko, Martin N. Zhang, Irma Larma and Kevin Li for technical assistance.

\section{Conflict of interest statement}

The authors declare no conflict of interest.

\section{Funding}

This work was supported by grants from the National Health and Medical Research Council (APP634352), the Medical Research Foundation of Royal Perth Hospital, and the Cancer Council of Western Australia. Evan Ingley received support from the Cancer Council of Western Australia, The Harry Perkins Institute of Medical Research, Sock-it-toSarcoma Research Foundation and the Hollywood Private Hospital Research Foundation, and the MACA Ride to Conquer Cancer. Margaret L. Hibbs is supported by a Senior Research Fellowship (APP603124) from the National Health and Medical Research Council, Australia.

\section{Abbreviations used:}

Epo, erythropoietin; Epo-R, Epo-receptor; PHZ, phenylhydrazine; STAT, signal transducer and activator of transcription; SFK, Src family kinases; Cbp, Csk binding protein; SOCS, suppressor of cytokine signaling. 


\section{References}

1. Witthuhn B, Quelle F, Silvennoinen O, et al. JAK2 associates with the erythropoietin receptor and is tyrosine phosphorylated and activated following stimulation with erythropoietin. Cell. 1993;74(2):227-236.

2. Wakao H, Harada N, Kitamura T, Mui AL, Miyajima A. Interleukin-2 and erythropoietin activate Stat5/MGF via distinct pathways. EMBO J. 1995;14(11):2527-2535. 3. Lecoq-Lafon C, Verdier F, Fichelson S, et al. Erythropoietin induces the tyrosine phosphorylation of GAB1 and its association with SHC, SHP2, SHIP, and phosphatidylinositol 3-kinase. Blood. 1999;93(8):2578-2585.

4. Bao HF, Jacobs-Helber SM, Lawson AE, Penta K, Wickrema A, Sawyer ST. Protein kinase B (c-Akt), phosphatidylinositol 3-kinase, and STAT5 are activated by erythropoietin (EPO) in HCD57 erythroid cells but are constitutively active in an EPO-independent, apoptosis-resistant subclone (HCD57-SREI cells). Blood. 1999;93(11):3757-3773.

5. Haq R, Halupa A, Beattie BK, Mason JM, Zanke BW, Barber DL. Regulation of erythropoietin-induced STAT serine phosphorylation by distinct mitogen-activated protein kinases. J Biol Chem. 2002;277(19):17359-17366.

6. Karur VG, Lowell CA, Besmer P, Agosti V, Wojchowski DM. Lyn kinase promotes erythroblast expansion and late-stage development. Blood. 2006;108(5):1524-1532.

7. Kuhrt D, Wojchowski DM. Emerging EPO and EPO receptor regulators and signal transducers. Blood. 2015;125(23):3536-3541.

8. Tilbrook PA, Ingley E, Williams JH, Hibbs ML, Klinken SP. Lyn tyrosine kinase is essential for erythropoietin-induced differentiation of J2E erythroid cells. EMBO J. 1997;16(7):1610-1619.

9. Ingley E, McCarthy DJ, Pore JR, et al. Lyn deficiency reduces GATA-1, EKLF and STAT5, and induces extramedullary stress erythropoiesis. Oncogene. 2005;24(3):336-343. 10. Slavova-Azmanova NS, Kucera N, Satiaputra J, et al. Gain-of-function Lyn induces anemia - appropriate Lyn activity is essential for normal erythropoiesis and Epo-receptor signaling. Blood. 2013;122(2):262-271.

11. Slavova-Azmanova NS, Kucera N, Louw A, et al. Lyn kinase plays important roles in erythroid expansion, maturation and erythropoietin receptor signalling by regulating inhibitory signalling pathways that control survival. Biochem J. 2014;459(3):455-466.

12. Tilbrook PA, Palmer GA, Bittorf T, et al. Maturation of erythroid cells and erythroleumkemia development are affected by the kinase activity of Lyn. Cancer Res. 2001;61(6):2453-2458.

13. Harder KW, Quilici C, Naik E, et al. Perturbed myelo/erythropoiesis in Lyn-deficient mice is similar to that in mice lacking the inhibitory phosphatases SHP-1 and SHIP-1. Blood. 2004;104(13):3901-3910.

14. Ingley E, Payne CJ, Murphy SV, et al. Src Family Kinases: regulating their activity, levels and identifying new pathways. Acta Biochimica Polonica. 2007;54(Supp 3):9-10.

15. Okada M, Nada S, Yamanashi Y, Yamamoto T, Nakagawa H. CSK: a proteintyrosine kinase involved in regulation of src family kinases. J Biol Chem.

1991;266(36):24249-24252.

16. Ogawa A, Takayama $\mathrm{Y}$, Sakai $\mathrm{H}$, et al. Structure of the carboxyl-terminal Src kinase, Csk. J Biol Chem. 2002;277(17):14351-14354.

17. Ingley E, Schneider JR, Payne CJ, et al. Csk-binding protein mediates sequential enzymatic down-regulation and degradation of Lyn in erythropoietin-stimulated cells. J Biol Chem. 2006;281(42):31920-31929.

18. Ingley E. Csk-binding protein can regulate Lyn signals controlling cell morphology. Int J Biochem Cell Biol. 2009;41(6):1332-1343. 
19. Patwardhan $P$, Resh MD. Myristoylation and membrane binding regulate c-Src stability and kinase activity. Mol Cell Biol. 2010;30(17):4094-4107.

20. Ingley E. Src family kinases: Regulation of their activities, levels and identification of new pathways. Biochimica et Biophysica Acta. 2008;1784(1):56-65.

21. Brdicka T, Pavlistova D, Leo A, et al. Phosphoprotein associated with glycosphingolipid-enriched microdomains (PAG), a novel ubiquitously expressed transmembrane adaptor protein, binds the protein tyrosine kinase csk and is involved in regulation of T cell activation. J Exp Med. 2000;191(9):1591-1604.

22. Kawabuchi M, Satomi Y, Takao T, et al. Transmembrane phosphoprotein Cbp regulates the activities of Src-family tyrosine kinases. Nature. 2000;404(6781):999-1003.

23. Nakada D, Oguro H, Levi BP, et al. Oestrogen increases haematopoietic stem-cell self-renewal in females and during pregnancy. Nature. 2014;505(7484):555-558.

24. Xu SL, Huo HX, Tan JEL, Lam KP. Cbp deficiency alters Csk localization in lipid rafts but does not affect T-cell development. Mol Cell Biol. 2005;25(19):8486-8495.

25. Klinken SP, Nicola NA, Johnson GR. 'In vitro"-derived leukemic cell lines induced by a raf- and myc-containing retrovirus differentiate in response to erythropoietin. Proc Natl Acad Sci USA. 1988;85(22):8506-8510.

26. Klinken SP, Holmes K, Fredrickson TN, Erner SM, Morse HC. Phenylhydrazine stimulates lymphopoiesis and accelerates abelson murine leukemia virus-induced pre-B cell lymphomas. J Immunol. 1987;139(3091-3098.

27. McLeod DL, Shreeve MM, Axelrad AA. Improved plasma culture system for production of erythrocytic colonies in vitro: quantitative assay method for CFU-E. Blood. 1974;44(4):5176-5534.

28. Xu S, Huo J, Tan JE, Lam KP. Cbp deficiency alters Csk localization in lipid rafts but does not affect T-cell development. Mol Cell Biol. 2005;25(19):8486-8495.

29. Chen K, Liu J, Heck S, Chasis JA, An X, Mohandas N. Resolving the distinct stages in erythroid differentiation based on dynamic changes in membrane protein expression during erythropoiesis. Proc Natl Acad Sci USA. 2009;106(41):17413-17418.

30. Williams NK, Lucet IS, Klinken SP, Ingley E, Rossjohn J. Crystal structures of the Lyn protein tyrosine kinase domain in its Apo- and inhibitor-bound state. J Biol Chem. 2009;284(1):284-291.

31. Whiting RJ, Payne CJ, Satiaputra J, et al. Targeting Lyn tyrosine kinase through protein fusions encompassing motifs of $\mathrm{Cbp}$ (Csk-binding protein) and the SOCS box of SOCS1. Biochem J. 2012;442(3):611-620.

32. McGraw KL, Fuhler GM, Johnson JO, et al. Erythropoietin receptor signaling is membrane raft dependent. PLoS One. 2012;7(4):e34477.

33. Nakata K, Suzuki Y, Inoue T, Ra C, Yakura H, Mizuno K. Deficiency of SHP1 leads to sustained and increased ERK activation in mast cells, thereby inhibiting IL-3-dependent proliferation and cell death. Mol Immunol. 2011;48(4):472-480.

34. Jiao H, Berrada K, Yang W, Tabrizi M, Platanias LC, Yi T. Direct association with and dephosphorylation of Jak2 kinase by the SH2-domain-containing protein tyrosine phosphatase SHP-1. Mol Cell Biol. 1996;16(12):6985-6992.

35. Wickrema A, Uddin S, Sharma A, et al. Engagement of Gab1 and Gab2 in erythropoietin signaling. J Biol Chem. 1999;274(35):24469-24474.

36. Lynch DK, Daly RJ. PKB-mediated negative feedback tightly regulates mitogenic signalling via Gab2. EMBO J. 2002;21(1-2):72-82.

37. Zhu QS, Robinson LJ, Roginskaya V, Corey SJ. G-CSF-induced tyrosine phosphorylation of Gab2 is Lyn kinase dependent and associated with enhanced Akt and differentiative, not proliferative, responses. Blood. 2004;103(9):3305-3312.

38. Wu J, Meng F, Lu H, et al. Lyn regulates BCR-ABL and Gab2 tyrosine phosphorylation and $\mathrm{c}-\mathrm{Cb}$ protein stability in imatinib-resistant chronic myelogenous leukemia cells. Blood. 2008;111(7):3821-3829. 
39. Sidorenko SP, Law CL, Chandran KA, Clark EA. Human spleen tyrosine kinase p72Syk associates with the Src-family kinase p53/56Lyn and a 120-kDa phosphoprotein. Proc Natl Acad Sci USA. 1995;92(2):359-363.

40. Boudot C, Dasse E, Lambert E, et al. Involvement of the Src kinase Lyn in phospholipase C-gamma 2 phosphorylation and phosphatidylinositol 3-kinase activation in Epo signalling. Biochem Biophys Res Comm. 2003;300(2):437-442.

41. Subramaniam V, Vincent IR, Gardner H, Chan E, Dhamko H, Jothy S. CD44 regulates cell migration in human colon cancer cells via Lyn kinase and AKT phosphorylation. Exp Mol Pathol. 2007;83(2):207-215.

42. Zonta F, Pagano MA, Trentin L, et al. Lyn sustains oncogenic signaling in chronic lymphocytic leukemia by strengthening SET-mediated inhibition of PP2A. Blood. 2015;125(24):3747-3755.

43. Chen $\mathrm{R}$, Kim O, Yang J, et al. Regulation of Akt/PKB activation by tyrosine phosphorylation. J Biol Chem. 2001;276(34):31858-31862.

44. Hemmings BA, Restuccia DF. PI3K-PKB/Akt pathway. Cold Spring Harbor perspectives in biology. 2012;4(9):a011189.

45. Kile BT, Mason-Garrison CL, Justice MJ. Sex and strain-related differences in the peripheral blood cell values of inbred mouse strains. Mammalian genome : official journal of the International Mammalian Genome Society. 2003;14(1):81-85.

46. Chin H, Arai A, Wakao H, Kamiyama R, Miyasaka N, Miura O. Lyn physically associates with the erythropoietin receptor and may play a role in activation of the Stat5 pathway. Blood. 1998;91(10):3734-3745.

47. De Franceschi L, Tomelleri C, Matte A, et al. Erythrocyte membrane changes of chorea-acanthocytosis are the result of altered Lyn kinase activity. Blood. 2011;118(20):5652-5663.

48. Brunati AM, Bordin L, Clari G, Moret V. The Lyn-catalyzed Tyr phosphorylation of the transmembrane band-3 protein of human erythrocytes. Eur J Biochem. 1996;240(2):394-399.

49. Bakker WJ, Blazquez-Domingo $M$, Kolbus $A$, et al. FoxO3a regulates erythroid differentiation and induces BTG1, an activator of protein arginine methyl transferase 1 . J Cell Biol. 2004;164(2):175-184.

50. Kashii $\mathrm{Y}$, Uchida M, Kirito K, et al. A member of Forkhead family transcription factor, FKHRL1, is one of the downstream molecules of phosphatidylinositol 3-kinase-Akt activation pathway in erythropoietin signal transduction. Blood. 2000;96(3):941-949.

51. Bouscary D, Pene F, Claessens Y-E, et al. Critical role for PI 3-kinase in the control of erythropoietin-induced erythroid progenitor proliferation. Blood. 2003;101(9):3436-3443. 52. Marinkovic D, Zhang X, Yalcin S, et al. Foxo3 is required for the regulation of oxidative stress in erythropoiesis. J Clin Invest. 2007;117(8):2133-2144.

53. Xiao W, Ando T, Wang HY, Kawakami Y, Kawakami T. Lyn- and PLC-beta3dependent regulation of SHP-1 phosphorylation controls Stat5 activity and myelomonocytic leukemia-like disease. Blood. 2010;116(26):6003-6013.

54. Harder KW, Parsons LM, Armes J, et al. Gain- and loss-of-function Lyn mutant mice define a critical inhibitory role for Lyn in the myeloid lineage. Immunity. 2001;15(4):603615.

55. Dobenecker MW, Schmedt C, Okada M, Tarakhovsky A. The ubiquitously expressed Csk adaptor protein $\mathrm{Cbp}$ is dispensable for embryogenesis and T-cell development and function. Mol Cell Biol. 2005;25(23):10533-10542.

56. Imamoto A, Soriano P. Disruption of the csk gene, encoding a negative regulator of Src family tyrosine kinases, leads to neural tube defects and embryonic lethality in mice. Cell. 1993;73(6):1117-1124.

57. Ahn E, Lee H, Yun Y. LIME acts as a transmembrane adapter mediating BCRdependent B-cell activation. Blood. 2006;107(4):1521-1527. 
58. Hur EM, Son M, Lee OH, et al. LIME, a novel transmembrane adaptor protein, associates with p56lck and mediates T cell activation. J Exp Med. 2003;198(10):14631473.

59. Pfrepper KI, Marie-Cardine A, Simeoni L, et al. Structural and functional dissection of the cytoplasmic domain of the transmembrane adaptor protein SIT (SHP2-interacting transmembrane adaptor protein). Eur J Immunol. 2001;31(6):1825-1836.

60. Chong YP, Mulhern TD, Cheng HC. C-terminal Src kinase (CSK) and CSKhomologous kinase (CHK)--endogenous negative regulators of Src-family protein kinases. Growth Factors. 2005;23(3):233-244.

61. Cloutier JF, Veillette A. Association of inhibitory tyrosine protein kinase p50csk with protein tyrosine phosphatase PEP in T cells and other hemopoietic cells. EMBO J. 1996;15(18):4909-4918.

62. Akashi K, Traver D, Miyamoto T, Weissman IL. A clonogenic common myeloid progenitor that gives rise to all myeloid lineages. Nature. 2000;404(6774):193-197.

63. Ingley E, Chappell D, Poon SY, et al. Thyroid hormone receptor-interacting protein 1 modulates cytokine and nuclear hormone signaling in erythroid cells. J Biol Chem. 2001;276(46):43428-43434. 


\section{Figure legends}

Figure 1. $\mathrm{Cbp}^{-/-}$mice have altered bone marrow and spleen erythropoietic parameters. (A) Representative images of concentrated bone marrow aspirates from wildtype (WT) and $\mathrm{Cbp}^{-/-}$male mice (10-15 weeks old). (B) Flow cytometric analysis of the erythroid compartment of wild-type (WT) and $\mathrm{Cbp}^{-/-}$male bone marrow aspirates (10-15 weeks old). Bone marrow cells were stained for CD71, CD44 and Ter119 and proerythroblasts (ProE; CD71 high $/$ Ter119), erythroblasts (Ery; CD71 ${ }^{\text {low-high } / T e r 119^{+}}$) and mature red blood cells (RBC; CD71\%/Ter119 ${ }^{+}$) were enumerated (left panels). The erythroblast population was further analysed using CD44 and FSC to delineate stages of differentiation (right panels, from early erythroblasts, EryE, through maturing populations EryA, EryB, EryC). ${ }^{29}$ (C) Analysis of myeloid progenitor populations in the bone marrow of wild-type (WT) and $\mathrm{Cbp}^{-/-}$female mice (10-15 weeks old). Common myeloid progenitors (CMP), granulocyte/macrophage progenitors (GMP) and megakaryocyte/erythrocyte progenitors (MEP) were enumerated by flow cytometry. ${ }^{62}$ (D) Spleen wet weight of wildtype (WT) and $\mathrm{Cbp}^{-/-}$male and female mice (10-15 weeks old). (E) Representative images of spleen of wild-type (WT) and $\mathrm{Cbp}^{-/-}$male mice (10-15 weeks old). (F) Flow cytometric analysis of the erythroid compartment of wild-type (WT) and $C^{-/-}$male spleen cells (1015 weeks old), analysed as described in B above. All data is $n=5$ to $10,{ }^{*} p<0.05,{ }^{* *} p<0.01$, $@ p<0.10$.

Figure 2. Immortalized erythroblasts from $\mathrm{Cbp}^{-/-}$mice have enhanced viability and differentiation. (A) Morphological analysis of representative erythroid lines generated from $\mathrm{Cbp}^{+/+}(\mathrm{J} 2-\mathrm{WT})$ and $\mathrm{Cbp}^{-/-}\left(\mathrm{J} 2-\mathrm{Cbp}^{-/-}\right)$mice and stained with Wright's-Giemsa (scale bar $=5 \mu \mathrm{m})$. Bright field images were acquired at 40X magnification on an Olympus IX71 microscope using an Olympus DP70 camera. (B) Flow cytometric analysis of cell surface expression of CD71, CD44, CD117 and CD11b for J2-WT and J2-Cbp ${ }^{-/}$cells. (C) Proliferation rates of $\mathrm{J} 2-\mathrm{WT}$ and $\mathrm{J}_{2}-\mathrm{Cbp}^{-/}$cells in differentiation media $\left(\mathrm{IMDM} / \mathrm{T}_{3}\right.$-depleted FCS) in the presence of Epo $(1 \mathrm{U} / \mathrm{ml})$. (D) Viability in response to Epo in differentiation media (IMDM/ $\mathrm{T}_{3}$-depleted FCS) ${ }^{63}$ of $\mathrm{J} 2-\mathrm{WT}$ and $\mathrm{J} 2-\mathrm{Cbp}^{-/-}$cell lines at 0 and $24 \mathrm{~h}$. (E) Differentiation capacity (percentage of benzidine positive cells) of $\mathrm{J} 2-\mathrm{WT}$ and $\mathrm{J} 2-\mathrm{Cbp}^{-/-}$ cells when cultured with Epo $(1 \mathrm{U} / \mathrm{ml})$ in differentiation media (IMDM/T ${ }_{3}$-depleted FCS) at the times indicated. (F) Total haemoglobin production of J2-WT and J2-Cbp ${ }^{-/-}$cells when cultured in the absence or presence of Epo $(0.1-10 \mathrm{U} / \mathrm{ml})$ in differentiation media 
(IMDM/T 3 -depleted FCS), assayed by spectral scanning (OD418 $\mathrm{nm} / \mu \mathrm{g}$ total protein) of cell lysates at the times indicated. (G) Immunoblot analysis of cell lysates of J2-WT and $\mathrm{J} 2-\mathrm{Cbp}^{-/-}$cells with and without Epo $(1 \mathrm{U} / \mathrm{ml})$ in differentiation media (IMDM/T3-deleted FCS) at the time points indicated. Membranes were probed with antibodies directed against the erythroid isoform of the rate-limiting haem synthesizing enzyme ALAS-E, $\beta$ globin, GAPDH, the erythroid transcription factor GATA-1 and $\beta$-actin as a loading control. (H) Dose-response of Epo-induced maintenance of cell surface transferrin receptor levels (CD71) on J2-WT and $\mathrm{J} 2-\mathrm{Cbp}^{-/-}$cells cultured in differentiation media $\left(\mathrm{IMDM} / \mathrm{T}_{3}\right.$-depleted FCS). Both J2-WT and J2-Cbp ${ }^{-/-}$cells are $>95 \%$ positive for CD71 at time 0 (see panel B), and without Epo, levels decrease rapidly in differentiation media. Experiments are performed in triplicate, ${ }^{*} p<0.05$.

Figure 3. Lyn phosphorylates Cbp creating binding sites for Lyn/Src and Csk, and loss of Cbp increased Lyn activity and Epo-induced signalling. (A) Immunoblot analysis of phosphorylated GST-Cbp over time in the presence of the purified kinase domain of Lyn. The level of tyrosine phosphorylation was assayed by anti-pY (Y100) immunoblotting at the time points shown. Cbp levels were assayed by coomassie blue G250 staining. (B) Detection of high affinity direct binding of NusA fusions of the SH2 domains of Lyn and Src to phosphorylated GST-Cbp using bio-layer interferometry. Controls using NusA, GST and un-phosphorylated GST-Cbp were included. Association of GST/GST-Cbp or GST-pCBP was commenced at time point "a" and disassociation commenced at time point "d". (C) Immunoblotting and direct blotting analysis of lysates from HEK293T cells transfected with expression constructs for constitutively active Lyn (LynY508F) and myc-tagged Cbp (WT, Y314F, Y381/409F) as indicated. Lysates were analysed by immunoblotting to detect Cbp (myc-tag) expression and total pY levels of the expressed Cbp (pY100). Membranes were also probed with the fluorescently labeled NusA-fusion of the SH2 domain of Csk. (D) Detection of high affinity direct binding of the NusA fusion of the SH2 domain of Csk to phosphorylated GST-Cbp using bio-layer interferometry. The control was NusA with GST-pCbp. Association of GST-pCbp was commenced at time point "a" and disassociation commenced at time point "d". (E) Immunoblot analysis of lysates from J2-WT and J2-Cbp ${ }^{-/-}$cells stimulated with Epo (5U/ml) for the times indicated. Raft (R) and non-raft (NR) membrane fractions were prepared as described in materials and methods. Blots were probed with antibodies directed against Lyn, the activation loop phospho-tyrosine motif of SFKs (Y416), and phosphorylated STAT5 (pSTAT5). Confirmation of membrane fractionation was undertaken using the non- 
raft marker transferrin receptor (TfR) and the raft-marker caveolin-1 (Cav-1), and $\beta$-actin was used as a loading control. (F) Immunoblot analysis of phospho-tyrosine dynamics during Epo induction in J2-WT and J2-Cbp ${ }^{-/-}$cells. Time course (0, 10, $30 \mathrm{~min}$ ) of Epoinduced $(\mathrm{Epo}, 5 \mathrm{U} / \mathrm{ml})$ total phospho-tyrosine protein changes. Prominent changes in phospho-proteins between the cell lines are indicated (arrow heads, grey= $\mathrm{J}_{2} \mathrm{Cbp}^{-/-}$ prominent, black=J2-WT prominent).

Figure 4. Immortalized erythroblasts lacking Cbp display enhanced STAT5, Akt, Fox03, SHP-1, and PLC $\gamma 1$ tyrosine phosphorylation, as well as reduced Erk1/2 activation, and GAB2 tyrosine phosphorylation. (A) Proximal Epo-R signaling dynamics during Epo induction in J2-WT and $\mathrm{J} 2-\mathrm{Cbp}^{-/-}$cells. Immunoblot analysis of cell lysates from $\mathrm{J} 2-\mathrm{WT}$ and $\mathrm{J} 2-\mathrm{Cbp}^{-/-}$cell lines for the signaling molecules indicated before and after 10 and 30 minutes of Epo-stimulation $(5 \mathrm{U} / \mathrm{ml})$. The phosphorylation status and total levels of Epo-R, JAK2, STAT5, Akt and Erk1/2 were analysed, with $\beta$-actin as a loading control. (B, C) Downstream Epo-R signaling dynamics during Epo induction in J2WT and ${\mathrm{J} 2-\mathrm{Cbp}^{-/}}^{-/}$cells. Immunoblot analysis of cell lysates of $\mathrm{J} 2-\mathrm{WT}$ and $\mathrm{J}^{-}-\mathrm{Cbp}^{-/-}$cell lines for the signaling molecules and down-stream effectors indicated before and after 10 and 30 minutes of Epo-stimulation $(5 \mathrm{U} / \mathrm{ml})$. The phosphorylation status of the inactivation (Csk-mediated) Y508 site of Lyn, and total Lyn levels were analysed. Additionally, the phosphorylation status of SHP-1, SHP-2, GAB2, PLC $\gamma 1$, FoxO3, GSK $\alpha / \beta$, BAD were analysed as well as total levels of SHP-2, GAB2, BAD, BClXL, SOCS1 and SOCS3, with $\beta$ actin as loading control. Immunoblot analysis was performed on two independent experiments producing equivalent results.

Figure 5. $\mathrm{Cbp}^{-/-}$cells have altered translational control signaling, and Akt shows a strong association with Lyn in $\mathbf{C b p}^{-/-}$cells. (A) Immunoblot analysis of lysates from J2WT and $\mathrm{J} 2-\mathrm{Cbp}^{-/-}$cells with and without Epo $(5 \mathrm{U} / \mathrm{ml})$ at the time points indicated. Blots were probed with antibodies to the signaling (pEpoR/EpoR, pSFK416 motif, Lyn, pAktY315/pAktS473/Akt) and translational control proteins (p70S6K, pelF4E, p4BE-BP1, pelF2 $\alpha$, pS6) as indicated; $\beta$-actin was used as a loading control. (B) Immunoblot analysis of Akt-immunoprecipitates and cell lysates of J2-WT and J2-Cbp ${ }^{-/-}$cells with and without Epo $(5 \mathrm{U} / \mathrm{ml})$ at the time points indicated. Akt was immunoprecipitated from lysates at the indicated time points using anti-Akt antibodies/Protein-G agarose and blots probed for the association of Lyn and active Lyn/SFKs (pY416 motif), with Akt as a loading control. Blots of pSFK and Lyn from Akt-IPs were quantitated and levels relative to Akt in the IP is 
shown. Values significantly different between J2-WT and J2-Cbp ${ }^{-/-}$time points are indicated $\left({ }^{*} \mathrm{p}<0.05\right)$. Blots of lysates were also probed with antibodies to signaling molecules (pSTAT5/STAT5, pERK1/2/Erk1/2, pFoxO3, pAkt/Akt, Lyn, and $\beta$-actin as loading control) as indicated (lower panel). Immunoblot analysis was performed on two independent experiments producing equivalent results.

Figure 6. Elevated Akt/FoxO3 signalling during Epo-induced differentiation of $\mathrm{Cbp}^{-/-}$ cells, and signaling alterations in primary $\mathrm{Cbp}^{-/-}$erythroblasts. (A) Immunoblot analysis of cell lysates of J2-WT and $\mathrm{J} 2-\mathrm{Cbp}^{-/-}$cell lines, for the signaling molecules indicated (pAkt/Akt, pSTAT5/STAT5, pERK1/2/Erk1/2, pFoxO3, FoxO3, pGSK $\alpha / \beta$, $\mathrm{pBAD} / \mathrm{BAD}, \mathrm{Bcl}_{\mathrm{XL}}, \mathrm{p} 27 \mathrm{Kip} 1$, and $\beta$-actin as loading control), cultured in differentiation media (IMDM/T 3 -depleted FCS) with and without Epo $(1 \mathrm{U} / \mathrm{ml})$ at 0 and $48 \mathrm{~h}$. Immunoblot analysis was performed on two independent experiments producing equivalent results. (B) Immunoblot analysis of cell lysates of $\mathrm{Cbp}^{+/+}$and $\mathrm{Cbp}^{-/-}$spleen erythroblast cells isolated from PHZ-treated mice (day 4 post treatment), before and after 10 and 30 minutes of Epostimulation $(5 \mathrm{U} / \mathrm{ml}$ ) for the signaling molecules indicated (pEpoR/EpoR, pSTAT5/STAT5, pAkt/Akt, pFoxO3/FoxO3, pErk1/2, Erk1/2, pSHP-1, pSHP-2/SHP-2, pGAB2/GAB2, with $\beta$ actin as loading control). Blots of pFoxO3 and FoxO3 were quantitated and levels of pFoxO3 relative to total FoxO3 is shown. Values significantly different between J2-WT and $\mathrm{J} 2-\mathrm{Cbp}^{-/-}$time points are indicated $\left({ }^{*} \mathrm{p}<0.05\right)$.

Figure 7. Schematic of function and consequences of loss of Cbp on erythropoiesis. (A) Model of Cbp control of Lyn and intersection of Epo-R signaling. Thickness and darkness of arrows indicates proposed relative intensity of signaling connections. Greenfilled circle/Y indicates activating phospho-tyrosine events. Red-filled circle/ $Y$ indicates inhibitory phospho-tyrosine events. Red or black crosses indicate inhibitory actions. Yellow-filled circle/S indicates inhibitory serine phosphorylation events. (B) Model of the consequential effects of loss of Cbp on SFK/Lyn regulation and erythropoiesis. Left panel indicates the ability of Cbp to restrict SFK/Lyn activity and consequently maintain a transient viability signal during erythroid differentiation; right panel illustrates the effects of loss of Cbp on this process. 


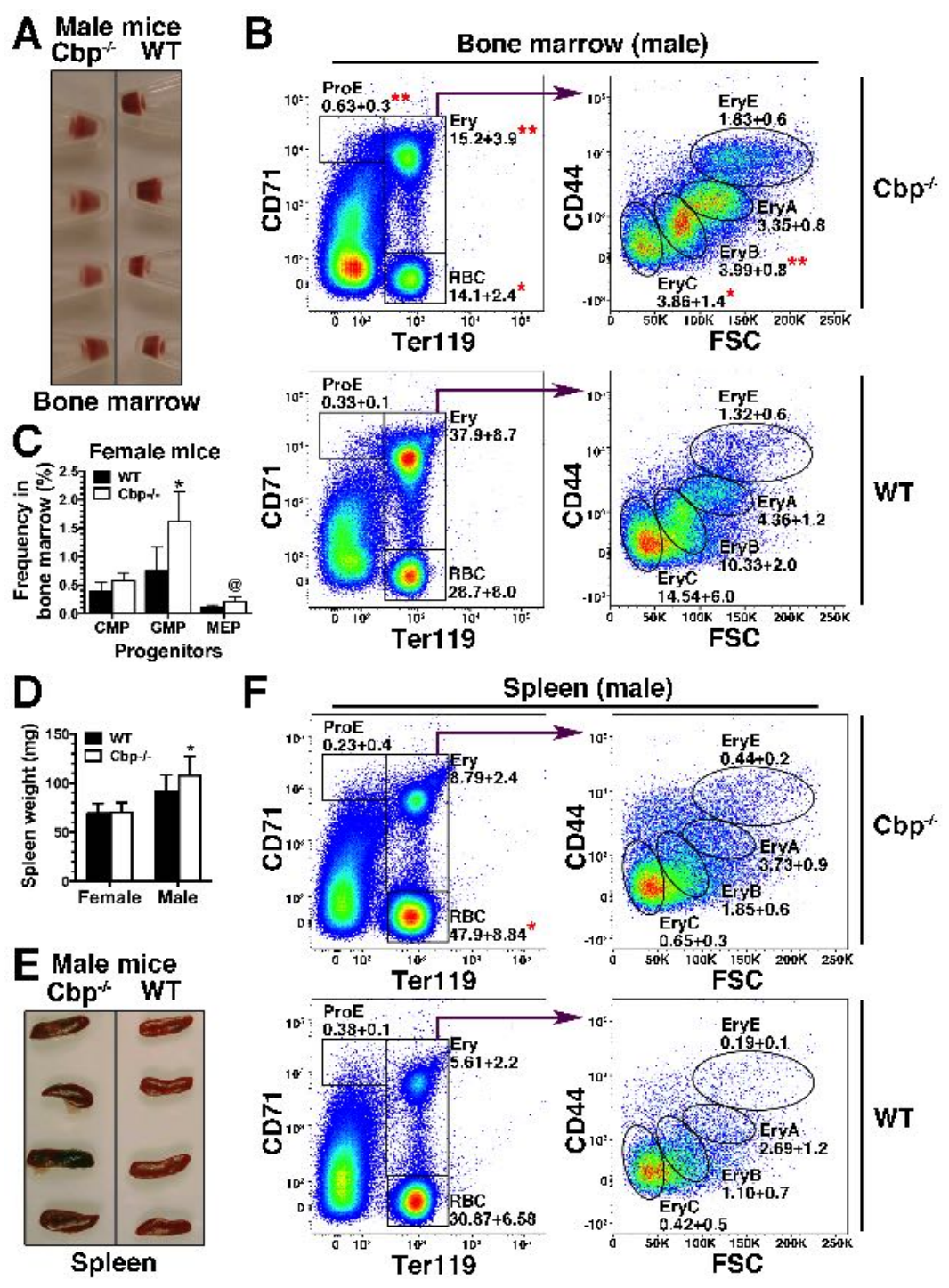

Figure 1 


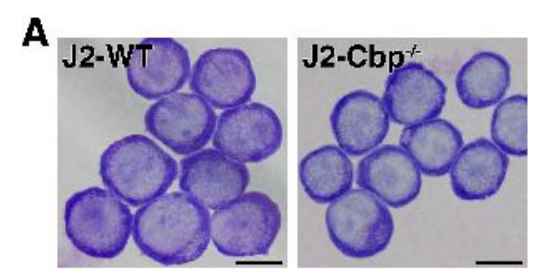

B
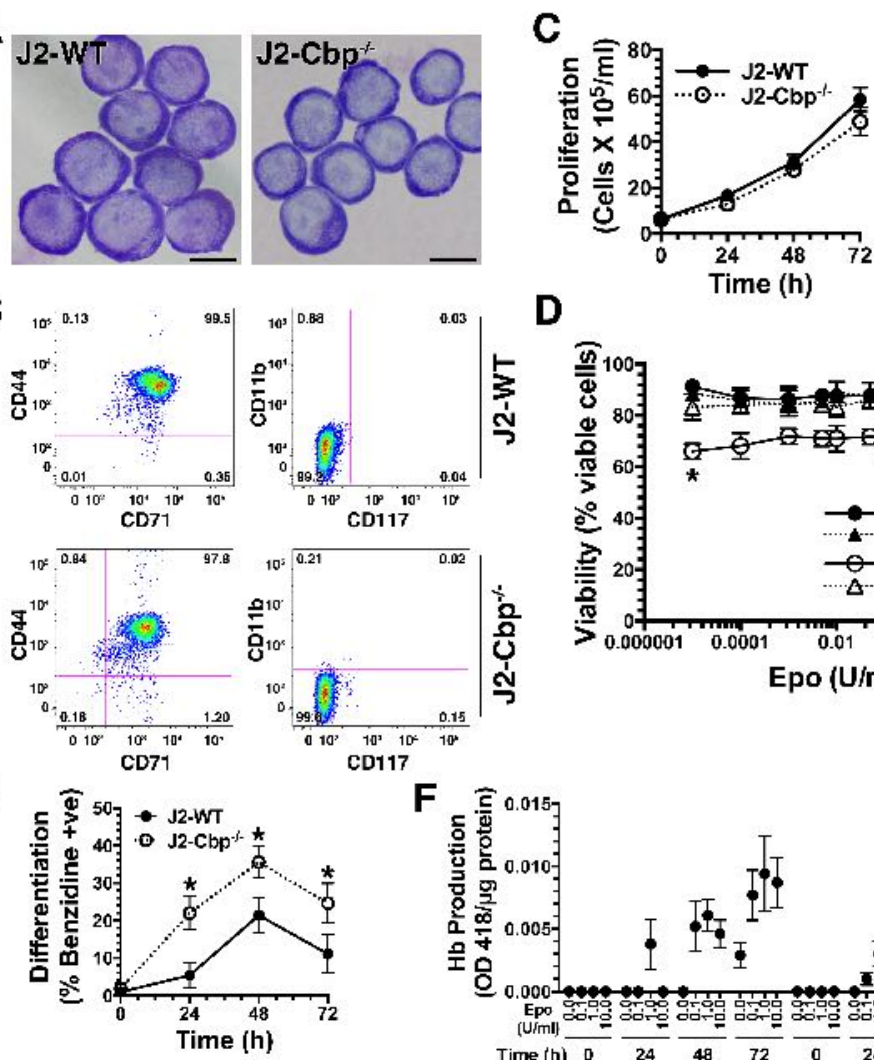

D
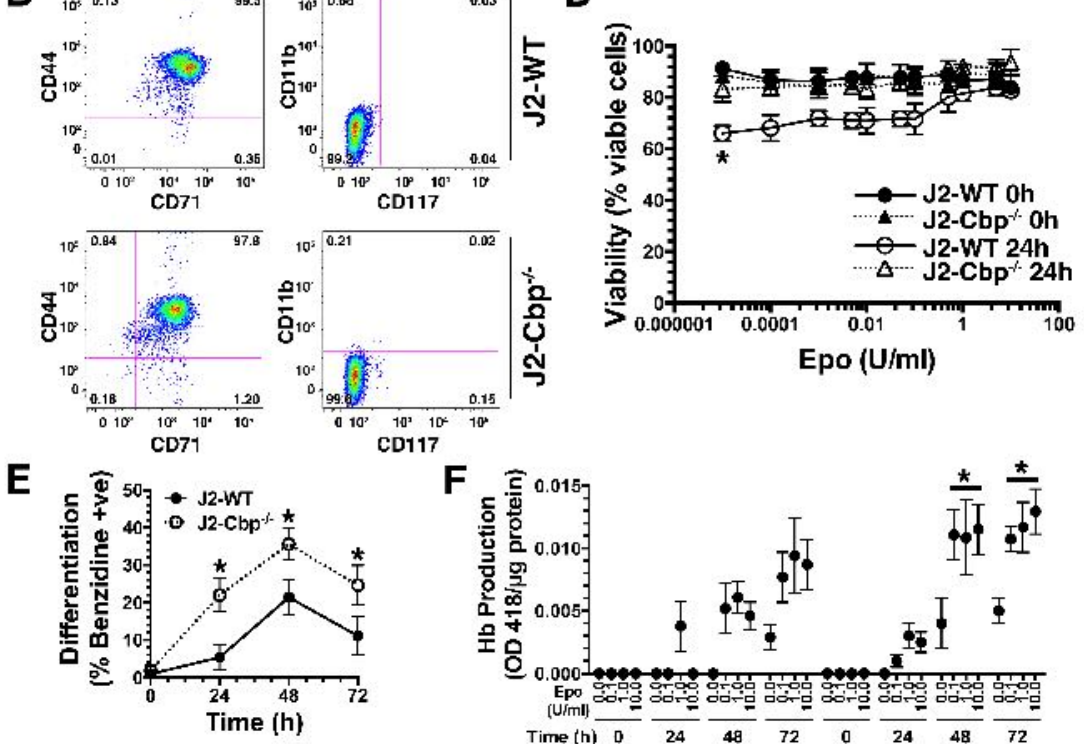

F

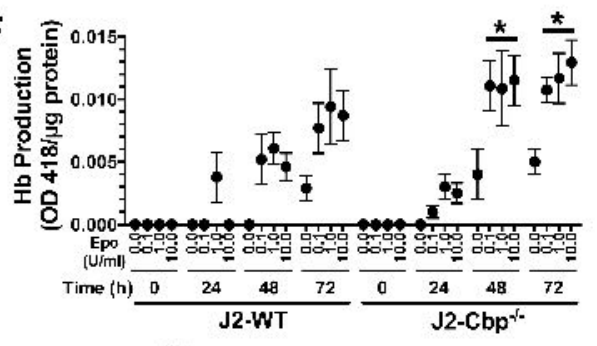

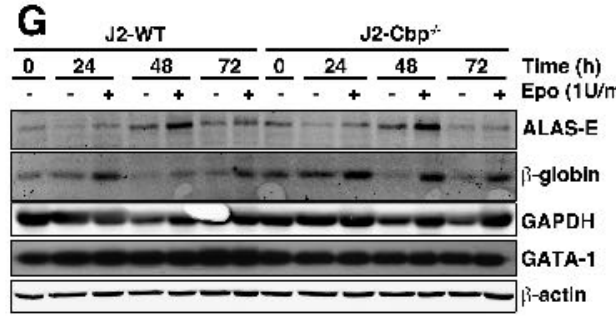

H

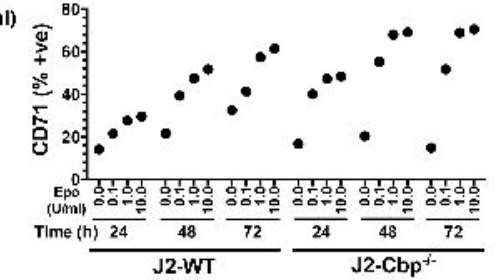

Figure 2 


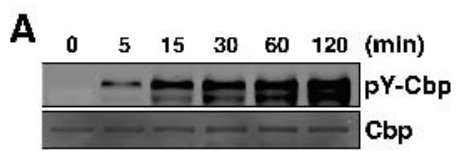

C + - - - + - - CbpWT

$-+-\quad-+-$ CbpY314F

-++-+-+ CbpY381/409F

$-\quad-++++$ LynY508F

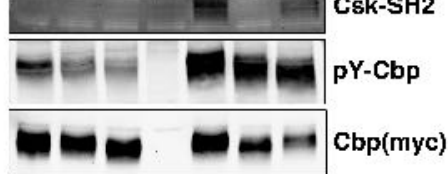

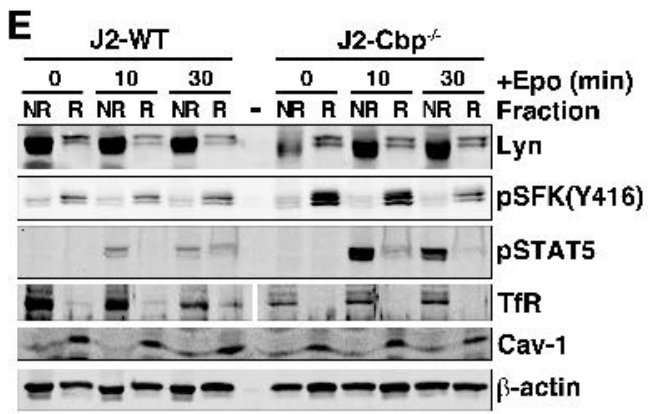

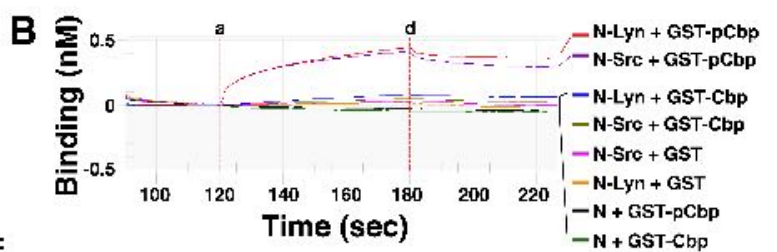

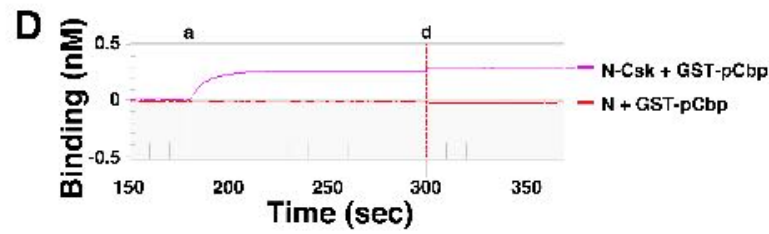

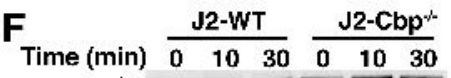

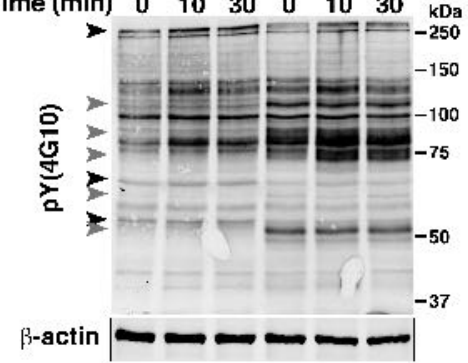

Figure 3 


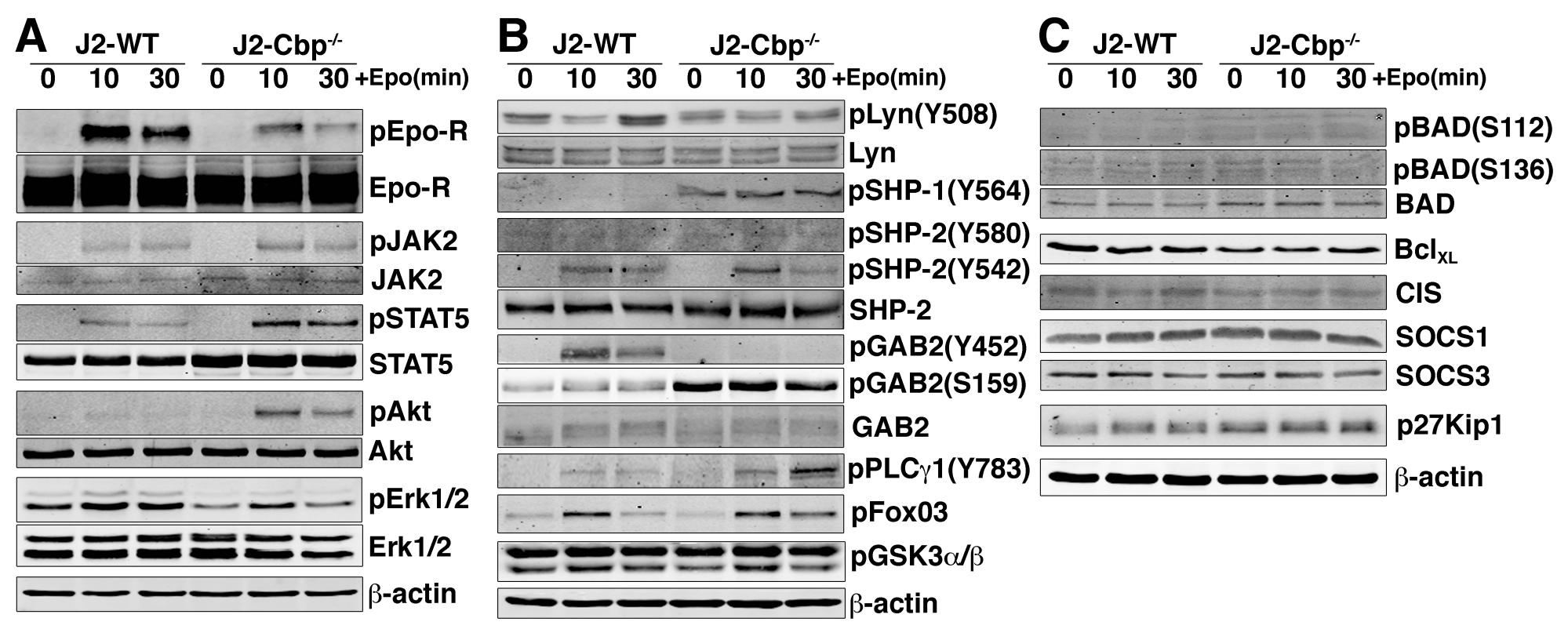

Figure 4 


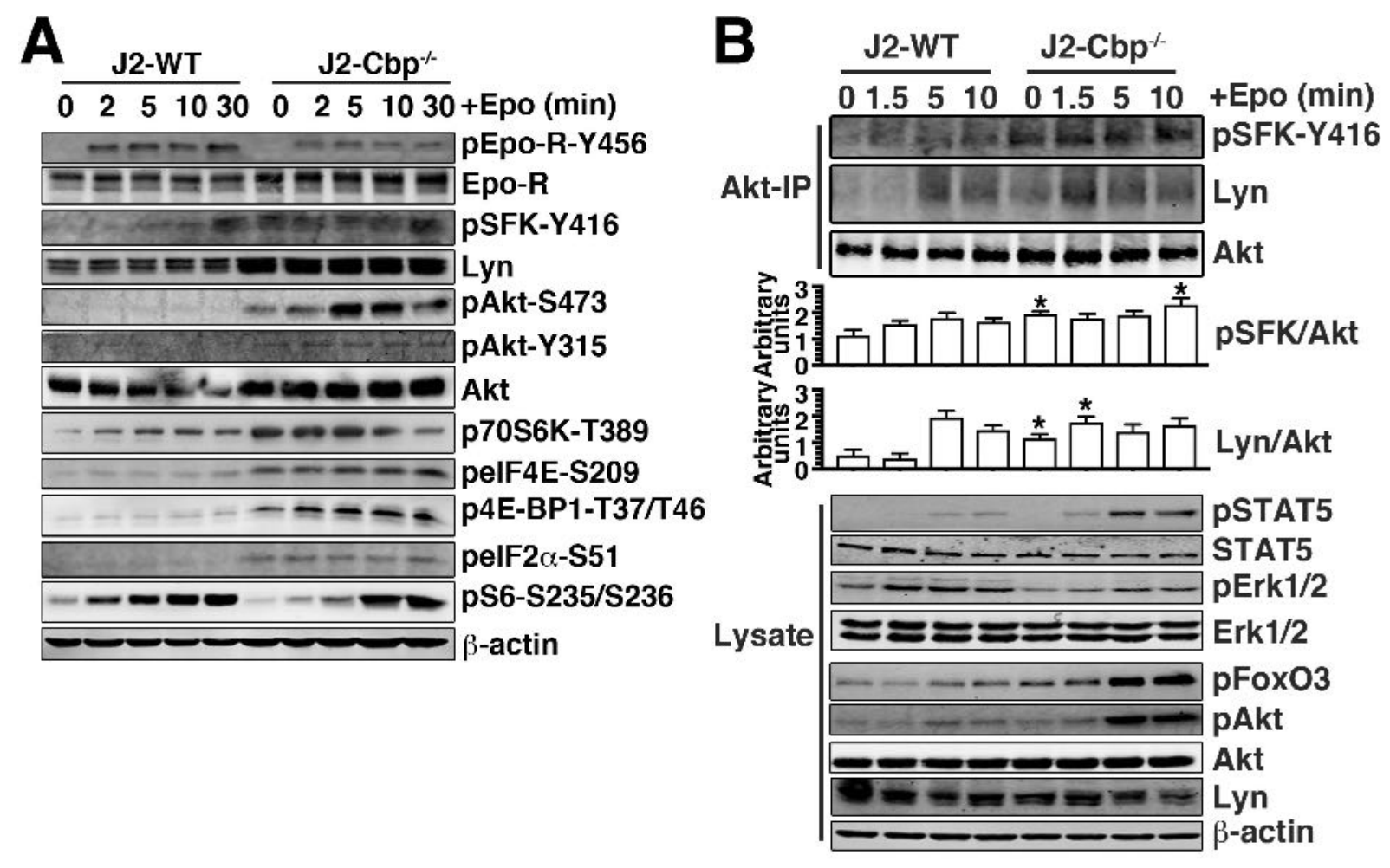

Figure-5 


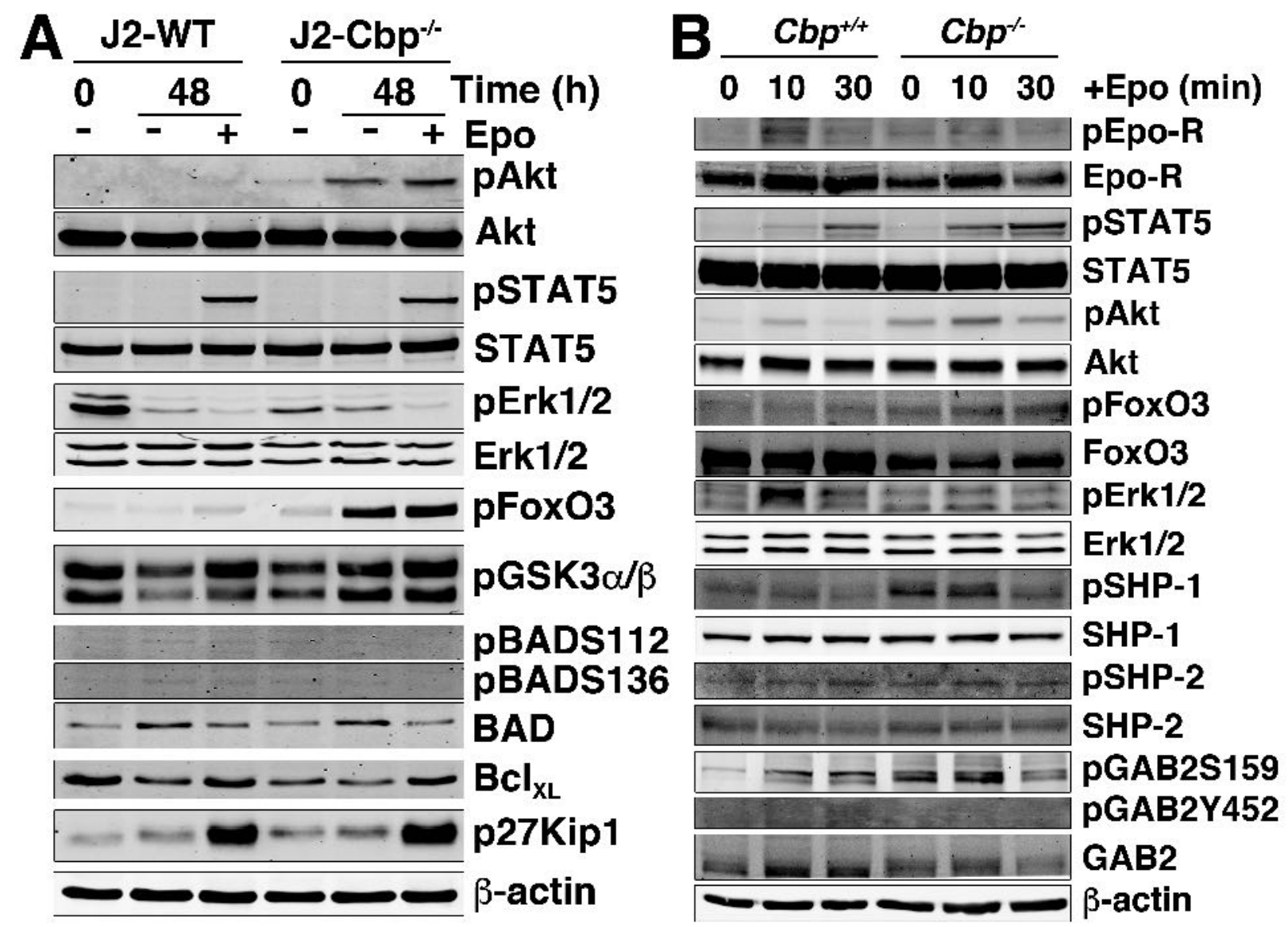

Figure 6 


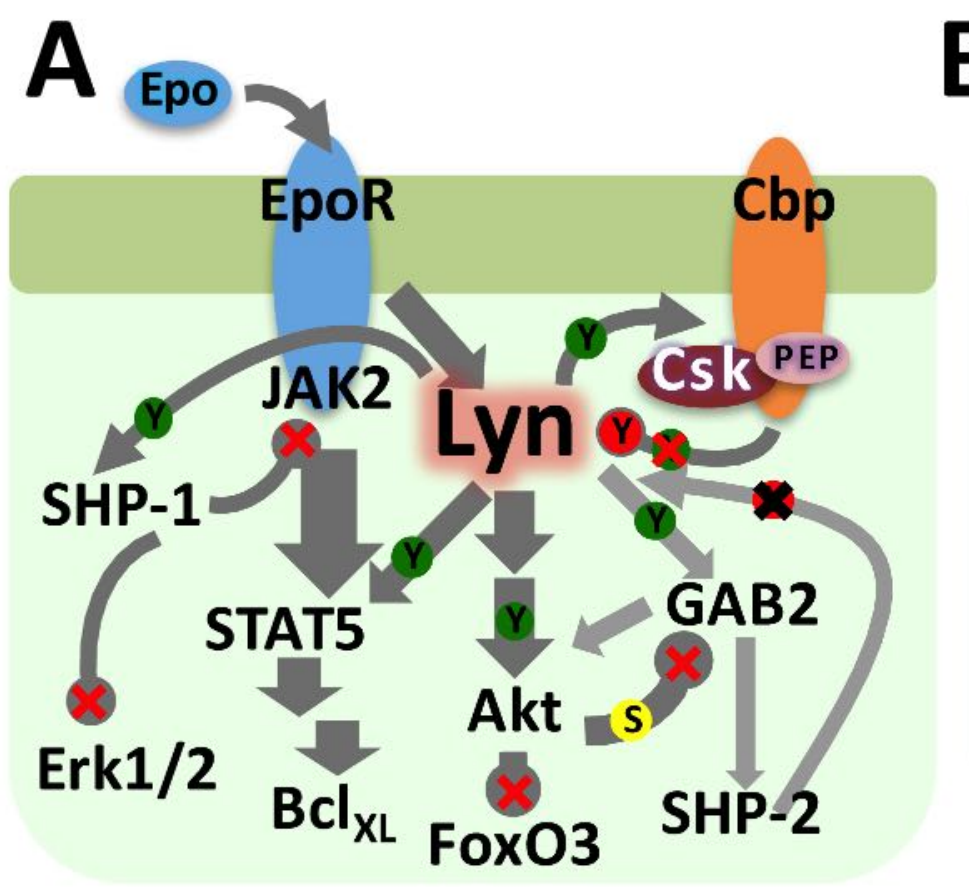

$\mathrm{Cbp}^{+/+}$

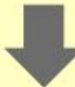

Dynamic SFK/Lyn regulation

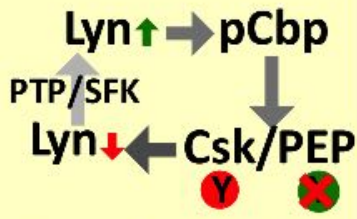

Transient viability signal during differentiation
$\mathrm{Cbp}^{\%}$

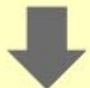

Blunted SFK/Lyn regulation

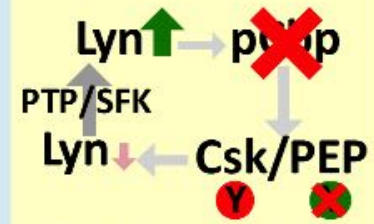

Sustained viability signal during differentiation

Figure 7 